\title{
Follow-Up: The Stepchild of the Guidance Family
}

\author{
GEORGE E. MYERS \\ Professor Emeritus of Education, University of Michigan
}

$\mathrm{T}$ HE FOLLOW-UP SERVICE of the guidance program is like Mark Twain's weather. Everybody talks about it but nobody does anything about it.

Of course this is only a half-truth. Or should one say a 90 per cent truth? A few people have done something about the followup service, though very little in comparison with what might be done.

Let it be clearly understood that the service under consideration, as far as carefully defined vocational guidance is concerned, is that which has been given to one who has already been assisted by the vocational information, self-inventory, personal data collecting, counseling, vocational preparatory and placement services in choosing, preparing for, and entering upon an occupation. The follow-up service is for the purpose of assisting the particular individual to progress in his chosen vocation.

This limitation of the term involves no reflection on the numerous follow-up studies of an entire graduating class or other large group. Such studies may furnish valuable data regarding the effectiveness of the guidance program, show up curriculum strengths and weaknesses, and supply material for use in gaining popular support for the program. One may well be disturbed by the thought that the 25 to 40 per cent of the group who did not return their questionnaires might have supplied information startlingly more significant than was obtained. Also, it must be kept in mind that such studies have little value unless the information obtained is actually used to improve conditions. Despite their limitations let more of these studies be made and their results used to the best possible advantage.
However, follow-up studies must not be confused with, nor substituted for, the follow-up service. The former is a mass undertaking and the latter an individualized effort. The former is soon finished and gives a still picture of conditions at the time the study was made. The latter continues over a considerable period of time and gives a moving picture of conditions and needs at the same time that it serves these needs. Some of the information gathered through the former method might be used (but seldom is) in serving the needs of those individuals who return the questionnaires. For example, in a follow-up study of some 3,000 graduates of a state university made in the 1930's, it was found that a happy-go-lucky young woman teacher, only a few months out of college, was spending more hours each week on motion pictures, dancing, and bridge than on her teaching duties, and no time at all on unpaid community service. This young woman was not given the help she needed. However, the study was not made for that purpose. Nor was any organization available to give such help to her and her former students.

\section{What Help is Needed?}

In determining what kinds of help constitute an adequate follow-up service, it seems wise first to determine the natural groups into which young people fall when they leave high school at or before graduation.

One group consists of those who enter directly into occupational life. Another group includes those who seek employment but are unable to secure it for many weeks or months. Members of a third group transfer to other, usually higher, educational institu- 
tions. A fourth group is made up of young women who marry soon after leaving school. Still another group consists of young women who, not seeking employment or marrying, remain at home with their parents for a considerable length of time. Most of this fifth group finally marry or enter the employed group. The proportion in each of the five groups varies, depending on the economic level of the community, the general condition of business, and other factors.

\section{What Are the Pressing Needs} of Each Group?

The young worker needs help to realize the obligations he assumes when he becomes a worker. He must recognize that it is his duty to do an honest day's work, to conserve his employer's property, to cultivate an attitude of loyalty toward his employer, and to cooperate with him in maintaining wholesome working conditions. He must keep himself in good physical, mental, and emotional condition for his work, and fit himself as well as possible for the duties of his job. He should learn to work harmoniously with his fellow workers, to participate in and feel responsibility for the activities of the union or other organization of his working group, and to find his place and take his part as a young worker in the life of his community.

The young worker also needs help to see and take advantage of his opportunities; to prepare himself better for his job and.for promotion, through the means available in his working environment, or through evening classes, extension courses, correspondence study, or guided reading. Furthermore, he must be helped to carry forward his general and civic education in a systematic manner, participate in recreational activities, pursue a hobby, and engage in community service activities-all in accordance with his interests and abilities, and all suited to a worker in his type of occupation. Beyond his obligations as a worker, he should learn to contribute to the building of wholesome attitudes on the part of his associates toward their work, fellow workers, union, and employer.

He needs help in making a new choice of occupation and finding employment in it if the one in which he is engaged proves to be unsuitable, or in transferring from one employer to another in the same occupation if conditions with the first are unfavorable.

The needs of the unemployed group are more obvious in a period of business depression than when jobs are fairly plentiful. It will be recalled that in the 1930's the Civilian Conservation Corps and the National Youth Administration were organized on a national scale to relieve a desperate situation among unemployed young people. A youth unable to find a job needs help in keeping up his morale. He needs part-time work with pay, at public expense if necessary, but under local control and supervision. He needs help in finding ways to use his time profitably, in preparing himself for work he hopes to do, in continued general education, in wholesome recreation and hobbies, and in unpaid community service with public or private civic and social welfate agencies. And, to be sure, he needs help in obtaining regular employment in business or industry as soon as possible. His needs would then become those of the employed youth outlined above.

The young person in the higher education group must first have assistance in selecting the institution which he will attend-large or small, technical or general, expensive or inexpensive, etc., according to his interests, abilities, personality traits, and financial condition. He then needs further help in planning his program, making desirable living arrangements, choosing extra-curricular activities and recreations, and finding suitable social experiences - all to the end that life in the institution may contribute as much as possible to his development along wholesome lines.

Space will not be taken for a listing of the needs of the young women who marry soon after leaving school nor of those who, not working for wages, remain for a considerable time in the homes of their parents. Suffice it to say that both of these groups, especially those who marry soon after leaving school, need help in seeing and preparing for the varied duties of wife and homemaker. And. both need, especially the urmarried ones who stay at home, to be drawn into cultural, recreational, and community service activities along the lines of their individual inter- 
ests, aptitudes, and abilities. Too much of the potentially valuable time and abilities of these young women is now spent on movies, "soap operas," and bridge parties to the detriment of themselves and society.

\section{How Can the Needed Help Be Provided?}

How much of the needed help discussed above do young people now receive after leaving high school? Actually, very little, valuable as it would be to them and to their communities. And that little is given in a very haphazard manner. The local school system, the State Employment Service, colleges, employers, employee organizations, and numerous social agencies are all concerned with particular aspects of the problem, but none of these has attacked the problem as a whole, or even particular aspects of it, in a systematic manner.

- Nor has any one of them so far attempted to coordinate the feeble efforts of the others with its own. No doubt the higher education group receives more of the needed help than does any other group. But even in this case the help is far less than it might be. The basic weakness of the situation is that no single agency feels responsible for helping these young people. This is a typical case of "what is everybody's business is nobody's business." Substantial progress toward solving this important problem cannot be expected until responsibility for its solution is placed.

The public school system is in a more favorable position than any other agency to hold this responsibility and to coordinate the efforts of other agencies.

Nearly all of the youth who need the follow-up service spent some twelve years in these schools. A mass of significant information regarding each youth has been accumulated during that period. The job to be done is essentially a guidance job-vocational, educational, recreational, and community service guidance. It is merely a continuation of the school guidance program during a critical period in the lives of those who have been, or should have been, served by this program while they were still in school. The school system is the logical agency to give each youth assistance in the orientation process, until he becomes adjusted to out-of-school life.

However, school systems as now organized cannot possibly provide adequate follow-up service. They operate on the theory that their responsibility ends when a youth graduates or legally leaves school without graduating. Members of the high school staff then say, figuratively if not literally: "Goodbye and good luck. You're on your own now. Come back and see us some time." This done, they turn their already crowded attention to a new crop of students. Nor can an overburdened high school staff be expected to do more.

A new unit in the school system, as distinctive as the high school unit, is necessary if an adequate follow-up service is to be provided. The names and records of all who graduate or leave school without graduating, including all information gathered by the guidance department, should be turned over to this new unit. In fact, students should be transferred to the new unit as they are now transferred to senior high school. This unit might be called the Occupational Adjustment Center or Vocational Induction Agency, except that it is concerned with other needs besides vocational. Perhaps Community Life Induction Agency, or Orientation Center would be better. By whatever name it is known, its responsibility would be to serve the orientation needs of every youth who goes out from the high school. To be sure, some would require much help, others little, but the needs of each one should be studied and then served as well as possible.

\section{Duties of the New Unit}

Obviously, the duties of the new unit would be many and varied. Contacts would have to be made with each youth who joined any one of the five groups, calling his attention to the help the unit was prepared to give him. A great number of counseling interviews would be necessary. Frequent conferences and much correspondence with employers, colleges, employee organizations, and numerous social agencies would be essential. Much information regarding colleges and other educational institutions should be 
brought together for ready reference. A list of educational facilities available to those who do not go on with a full-time educational program-evening classes, extension courses, correspondence courses, etc.--should be prepared and kept up to date. It may be necessary to provide educational facilities in addition to those already available. Familiarity with the recreational facilities of the community, and with the opportunities for engaging in voluntary community service activities, would be necessary. A continuing inventory of full-time and part-time jobs in the community would be required. There would be referrals to employers and records kept of the results. The unit might find it wise to set up a part-time work program for the unemployed group, as was done by the National Youth Administration some years ago. Probably other duties which cannot be anticipated in advance will demand attention when the unit's staff comes face to face with its actual task.

The staff required to carry on the work of this unit in an efficient manner would of course depend on the size of the community. All that need be said here is that its director and all who work with him should be chosen with strict regard to their special fitness for the unique duties assigned to them.

It may be objected that youth would consider this program too paternalistic; that they would rather be on their own when school days are over, and that they would not make use of this new unit of the school system. It must be kept in mind that the purpose is to assist the individual in mapping his own course, not to map it for him; to be sure that he has the information and methods of procedure required in order to make his own decisions wisely, not to make decisions for him. If the unit's staff does its work well, with proper recognition of the individual's personality and responsibilities, a rapidly increasing number will gladly avail themselves of its services.

Another objection to developing an adequate follow-up service is its cost. It may be argued that school systems are unable to finance properly the work they are now doing and that this new program would necessitate heavy additional expenditures. There can be no doubt that the follow-up service would be expensive. But public school authorities have a way of finding money for an expansion of their activities when they become convinced that the expansion is highly desirable. Besides and this is very important-thecontacts with business and industry, labor groups, social agencies, and citizens in general which would be involved in carrying on an adequate follow-up service would bring to the public schools a popular support that is undreamed of at present. It may be added that out of the activities of the proposed new unit would come suggestions far more valuable for strengthening the school curriculum and the guidance program as a whole than any number of mass follow-up studies would provide.

If an automobile manufacturer finds it desirable and profitable to provide free service for a time on each of his products-replacing parts that prove to be defective, making necessary adjustments, and assuring himself that the product performs as expected-then certainly the public school system would find desirable and profitable a similar service for each of its infinitely more valuable products. It is high time for city school systems of the United States to do sometbing worthwbile about the follow-up service. This is too promising a member of the guidance family to be treated any longer as a stepchild.

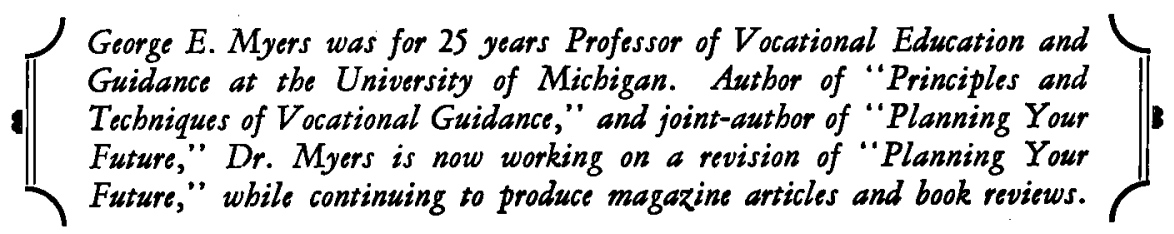

